\title{
Possible mechanisms of action in the positive effect of $\beta$ blockers in heart failure
}

\author{
M J Kendall
}

Department of Clinical

Pharmacology,

University of

Birmingham, Queen

Elizabeth Hospital,

Edgbaston,

Birmingham B15 2TH,

UK

M J Kendall

Correspondence to:

Professor Kendall

bham.ac.uk email: M.J.Kendall@

Sudden death is very common in heart failure, and its occurrence is considerably underestimated. Data from the second cardiac insufficiency bisoprolol study (CIBIS II) ${ }^{1}$ and the metoprolol $\mathrm{CR} / \mathrm{XL}$ randomised intervention trial in heart failure (MERIT-HF) ${ }^{2}$ on total mortality, total cardiovascular mortality, sudden death, and heart failure, show clearly that sudden death is extremely common in patients with cardiovascular disease.

In the CIBIS II and MERIT-HF trials, $47 \%$ (fig 1 ) and $64 \%$ (fig 2 ) of people who died from a cardiovascular cause died suddenly. The risk of sudden death is particularly high in the most common type of patient with heart failure, those with New York Heart Association (NYHA) class II and III symptoms (fig 3).

\section{Preventing coronary events}

In heart failure, the objective is to reduce symptoms and prolong life by making an impact on cardiac function, the underlying disease process, neurohumoral activation, and the risk of sudden death. $\beta$ Blockers might achieve several of these objectives although data published hitherto have not been interpreted as being particularly convincing on some of these points. The Medical Research Council (MRC) hypertension trial for example, which looked at coronary events, was accused of showing very little benefit for $\beta$ blockers, although there is a suggestion that propranolol was having an effect. ${ }^{3}$ However, Green's letter, published subsequently, showed a definite reduction in

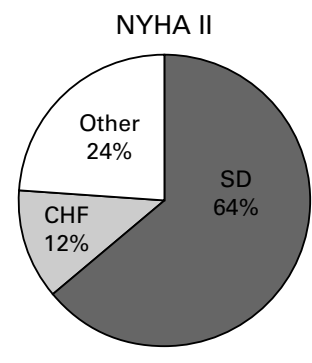

Number of deaths $n=103$

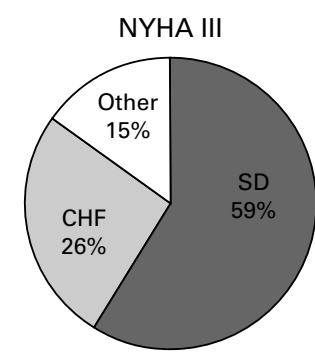

Number of deaths $\mathrm{n}=232$

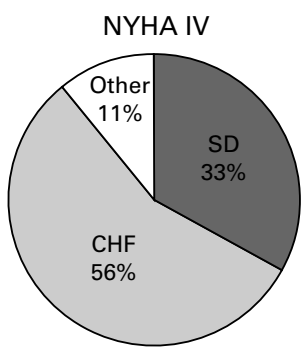

Number of deaths $\mathrm{n}=27$
(1 case unclassified)

Figure 3 MERIT-HF: mode of death by NYHA class. Reproduced from Hjalmarson et al, ${ }^{2}$ with permission of The Lancet Ltd.

Table 1 MRC trial: coronary events including silent myocardial infarction ${ }^{4}$

\begin{tabular}{llll}
\hline Type of treatment & $\begin{array}{l}\text { Number of } \\
\text { coronary events }\end{array}$ & $\begin{array}{l}\text { Rate per 1000 } \\
\text { patient years }\end{array}$ & p Value \\
\hline Bendrofluazide $(\mathrm{n}=4297)$ & 456 & 27.4 & $\mathrm{p}<0.001$ \\
Propranolol $(\mathrm{n}=4403)$ & 354 & 20.4 & $\mathrm{p}<0.05$ \\
Placebo $(\mathrm{n}=8654)$ & 814 & 23.9 & \\
\hline
\end{tabular}

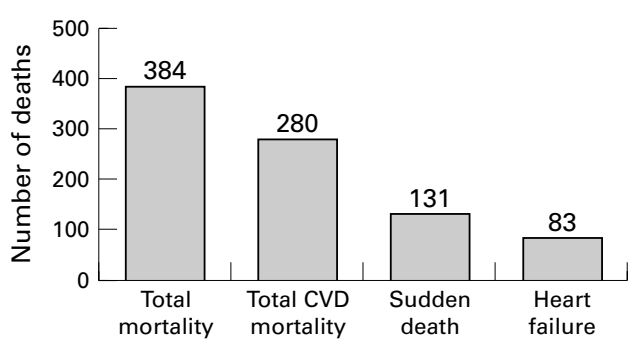

Figure 1 Sudden death rate in the CIBIS II trial. ${ }^{1}$

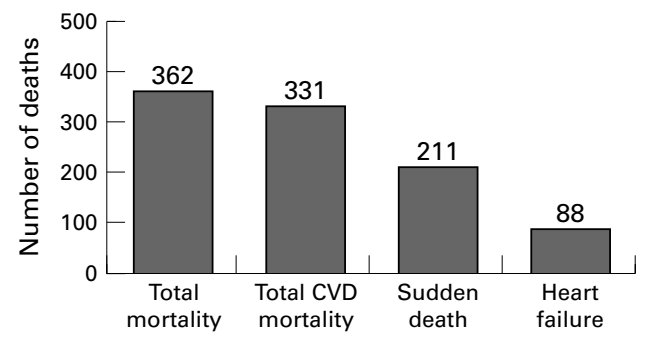

Figure 2 Sudden death rate in the MERIT-HF trial. ${ }^{2}$

the number of coronary events, including silent myocardial infarctions, among patients on propranolol (table 1). ${ }^{4}$

In the metoprolol atherosclerosis prevention in hypertensives (MAPHY) trial, diuretics and metoprolol had precisely the same impact on blood pressure and stroke but showed a considerable difference in terms of coronary events where metoprolol was superior. ${ }^{5}$ So it was already evident that $\beta$ blockers have an impact on reducing coronary events.

\section{Protection against sudden death}

Considerable excitement about the impact of $\beta$ blockers on sudden death in heart failure followed results of the CIBIS II and MERIT-HF studies. However, analysis of the data for sudden death rates from previous trials indicate that evidence for an effect of $\beta$ blockers has been available for some time (fig 4).

In the MRC trial there were significantly more sudden deaths in the diuretic group than in the propranolol group. ${ }^{4}$ Those on placebo also had a lower incidence of sudden death than those on diuretics. In the MAPHY trial, diuretics also showed a higher rate, and metoprolol a lower rate, of sudden death ${ }^{5}$. However, in the systolic hypertension in the elderly (SHEP) trial diuretics had no effect on sudden death, ${ }^{6}$ and in the systolic hypertension-Europe (SYST-EUR) trial calcium channel blockers also showed no effect. ${ }^{7}$ In the Swedish trial in old patients with hypertension (STOPHypertension), ${ }^{8}$ which used $\beta$ blockers and diuretics, there was a difference when compared with placebo. 


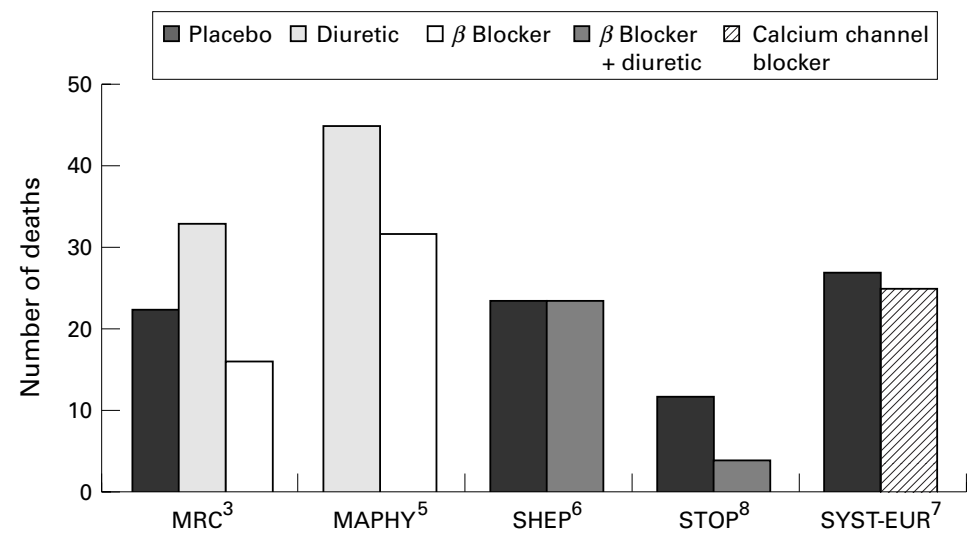

Figure 4 Sudden death rates in the Medical Research Council (MRC) trial, ${ }^{3}$, the metoprolol atherosclerosis prevention in hypertensives (MAPHY) trial, ${ }^{5}$ the systolic hypertension in the elderly (SHEP) trial, ${ }^{6}$ the systolic hypertension-Europe (SYST-EUR) trial, ${ }^{7}$ and the Swedish trial in old patients with hypertension (STOP). ${ }^{8}$

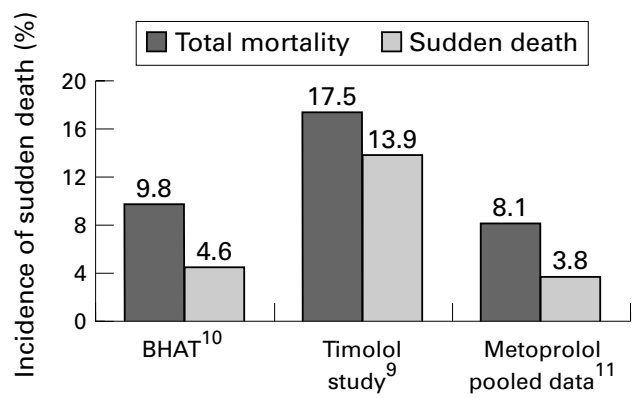

Figure 5 Incidence of sudden death in $\beta$ blocker post myocardial infarction trials. ${ }^{9-11}$

Many people who survive a myocardial infarct go on to die suddenly (fig 5). In the $\beta$ blocker post myocardial infarction trials, the impact of $\beta$ blockers in reducing the incidence of sudden death is quite notable (fig 6)..$^{-11}$ However, it is my belief that it may be only lipophilic $\beta$ blockers which work in this way. There are no data of this sort for atenolol, for example, and with sotalol there appears to be a slightly greater risk of dying suddenly. ${ }^{12}$

Taking an overview of 25 trials, totalling thousands of patients, the apparent impact of $\beta$ blockers on sudden deaths is remarkable when compared against controls. Held and Yusuf draw the same conclusion that in these trials $\beta$ blockers consistently show an impact on sudden death (fig 7 ). ${ }^{13}$

More recent studies confirm the effect. CIBIS II shows a $34 \%$ reduction for all cause mortality and a $44 \%$ reduction in sudden death on bisoprolol (fig 8). ${ }^{1}$ In the MERIT trial, the

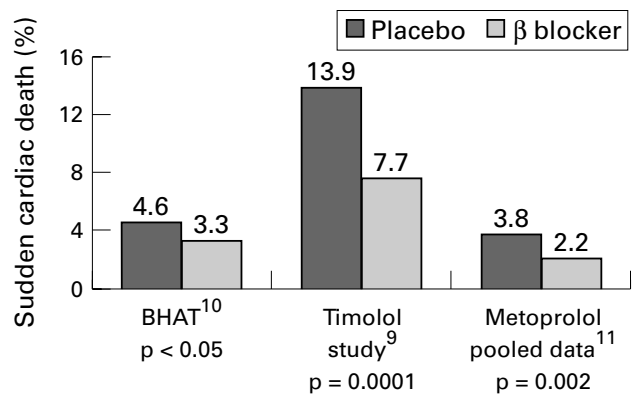

Figure 6 Secondary prevention (chronic studies) sudden cardiac death rate (\%). ${ }^{9-11}$

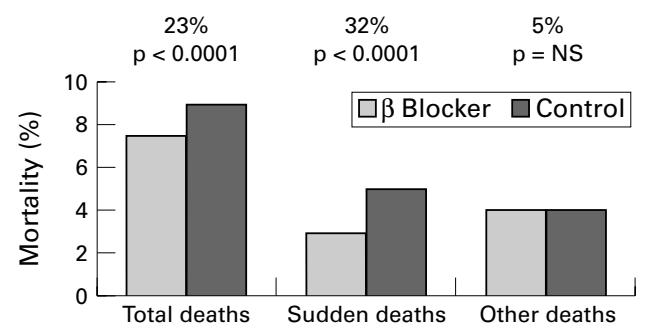

Figure 7 Overview of 25 trials of long term $\beta$ blockade after acute myocardial infarction. ${ }^{13}$

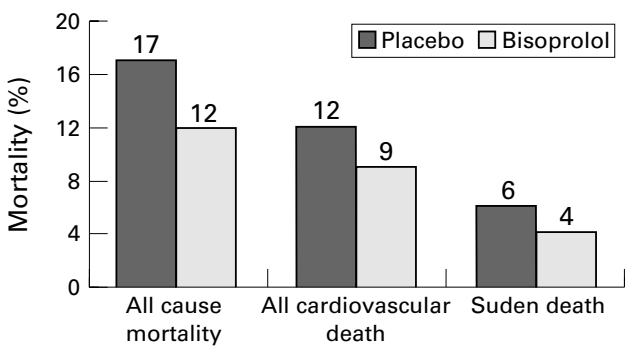

Figure 8 CIBIS II: impact on mortality. ${ }^{1}$

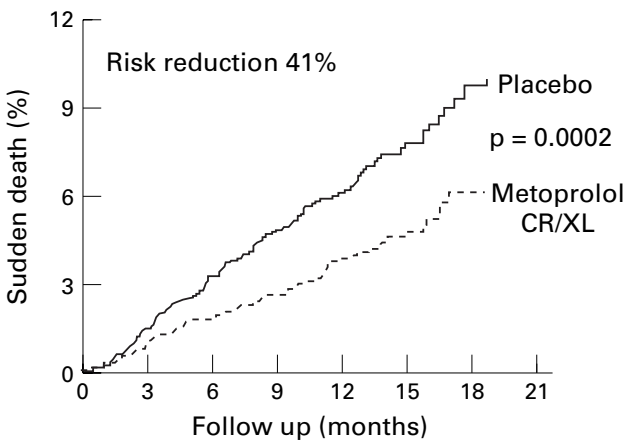

Figure 9 Merit-HF: impact on sudden death. ${ }^{2}$

impact of metoprolol on sudden death is a $41 \%$ reduction, a remarkably similar result.(fig 9). ${ }^{2}$

\section{Selecting a $\beta$ blocker}

How do $\beta$ blockers achieve this effect and what sort of $\beta$ blocker is the ideal choice? When selecting a $\beta$ blocker, it is probably advisable to choose a $\beta_{1}$ selective drug because that improves tolerability. It would also seem prudent to select one that is lipophilic. This point is debatable and many people are not convinced. However, it is noteworthy that the drugs for which there are the most data linking $\beta$ blockers with reductions in sudden deathpropranolol, timolol, metoprolol, bisoprololare more or less lipophilic drugs; nadolol, atenolol, and sotalol have not had the same impact on sudden death. This is not to suggest that the latter drugs do not act via $\beta$ blockade, or that they do not reduce blood pressure and infarct rates. They simply have not had the same impact on sudden death as the lipophilic $\beta$ blockers.

1 The cardiac insufficiency bisoprolol study II (CIBIS II): a randomised trial. Lancet 1999;353:9-13.

2 Hjalmarson A, Goldstein S, Fagerberg B, et al. Effect of metoprolol CR/XL in chronic heart failure: metoprolol $\mathrm{CR} / \mathrm{XL}$ randomised intervention trial in congestive heart failure (MERIT-HF). Lancet 1999.353.2001-7.

3 Medical Research Council Working Party. MRC trial of treatment of mild hypertension: principal results. BMF 1985;291:97-104. 
4 Green KG. British MRC trial of treatment for mild hypertension: a more favourable interpretation [letter]. Am hypertension: a more favo

5 Wikstrand J, Warnold I, Olsson G, et al. Primary prevention with metoprolol in patients with hypertension. Mortality results from the MAPHY study. $\mathscr{f} A M A 1988 ; 259$ : 1976-82.

6 SHEP Cooperative Research Group. Prevention of stroke by antihypertensive drug treatment in older persons with isolated systolic hypertension. $7 A M A$ 1991;265:3255-64.

7 Staessen JA, Fagard R, Thijs L, et al. Randomised double-blind comparison of placebo and active treatment for older patients with isolated systolic hypertension. Lancet 1997;350:757-64.

8 Dahlöf B, Lindholm LH, Hansson L, et al. Morbidity and mortality in the Swedish trial in old patients with hypertension (STOP-Hypertension). Lancet 1991;338: $1281-5$.
9 Norwegian Multicentre Study Group. Timolol-induced reduction in mortality and reinfarction in patients surviving acute myocardial infarction. $N$ Engl f Med 1981;304:801-7.

0 Beta Blocker Heart Attack Research Group. A randomize trial of propranolol in patients with acute myocardial infarction. 1. Mortality results. FAMA 1982;247:1707-13.

11 Olsson G, Wikstrand J, Warnold I, et al. Metoprolol-induced reduction in postinfarction mortality: pooled results from five double-blind randomized trials. Eur Heart 7 1992;13: $28-32$.

12 Julian DG, Jackson FS, Prescott RJ, et al. Controlled trial of sotalol for one year after myocardial infarction. Lancet 1982;i:1142-7.

13 Held PH, Yusuf S. Effects of beta-blockers and calcium channel blockers in acute myocardial infarction. Eur Heart f 1993;14:18-25. 